\title{
Pineal malignant neoplasm in association with hereditary retinoblastoma
}

\author{
CLARE STANNARD,' B K KNIGHT,' AND R SEALY' \\ From the Department of 'Radiotherapy and 'Pathology, Groote Schuur Hospital and University of Cape Town, \\ South Africa
}

SUMMARY A patient with unilateral hereditary retinoblastoma who was successfully treated at the age of 7 weeks developed a tumour in the pineal region two and a half years later. The initial response to radiation treatment of the latter lesion was not maintained. Subsequent necropsy findings are described. Clinically and pathologically this case represents an example of the recently described trilateral retinoblastoma. The response to treatment after early recognition was disappointing.

Several reports have described the occurrence of second malignancies in patients treated for bilateral retinoblastoma. ${ }^{1-12}$ One report ${ }^{3}$ included three patients with intracranial malignancies, of which one was clinically a pinealoma. In 1977 , Jakobiec et al. ${ }^{13}$ described two neuroblastic intracranial tumours in patients with retinoblastoma, one of which was a pineal tumour. More recently the association of a pineal tumour with bilateral retinoblastoma has been described and the concept of trilateral retinoblastoma suggested..$^{1+1 \times}$

The following case report illustrates the occurrence of a pineal neoplasm in a patient with hereditary unilateral retinoblastoma.

\section{Case report}

The patient was a boy whose mother and sister had both been treated for bilateral retinoblastoma. The pregnancy and delivery were normal. The eyes were examined under anaesthetic (EUA) at the age of 7 weeks because of the strong family history of retinoblastoma. A white fluffy lesion measuring $10.5 \times 9 \mathrm{~mm}$ was seen in the posterior pole of the left eye. It was situated over the macula and was close to but did not encroach on the optic disc. There were no other lesions of the left eye and there were no tumours in the right eye. There were no other

Correspondence to Dr Clare Stannard, Radiotherapy Department, Groote Schuur Hospital, Obscrvatory, 7925 Cape Town, Republic of South Africa. physical abnormalities. A diagnosis of retinoblastoma was made.

The patient was treated with dibromodulcitol $3.5 \mathrm{mg} / \mathrm{kg}$ body weight and procarbazine $75 \mathrm{mg} / \mathrm{m}^{2}$; both drugs were given daily for 33 days. EUA after 11 days showed that the tumour had regressed from the optic disc. After a further 10 days radiation treatment was started with $250 \mathrm{kV} x$-rays, $3.5 \mathrm{~mm}$ copper half value layer, and a tumour dose of 3095 cGy given. This treatment was given in 17 fractions over a period of 23 days through planned fields to the posterior pole of the left eye. The time dose fraction factor (TDF) was 60 allowing for a relative biological effect of $1 \cdot 175$ compared with cobalt rays.

Five weeks after completion of radiotherapy EUA showed further regression and calcification of the tumour. It measured $7.5 \times 6 \mathrm{~mm}$, and the medial edge was $3 \mathrm{~mm}$ lateral to the optic disc. Chemotherapy was resumed in the same dosages as previously and was given three times a week for a further three months.

Subsequent EUAs revealed that the tumour in the left eye remained static, and no tumour was ever detected in the right eye.

At the age of 2 years and 8 months the child developed headaches, episodes of vomiting, and became irritable and lethargic. On examination there was meningism but no other neurological sign. EUA showed that the fundi were unchanged. Computerised tomographic (CT) scan confirmed the presence of a calcified area in the left posterior fundus lateral to the optic disc (Fig. 1). It also showed a $15 \times 22 \mathrm{~mm}$ enhancing lesion in the region of the pineal gland 


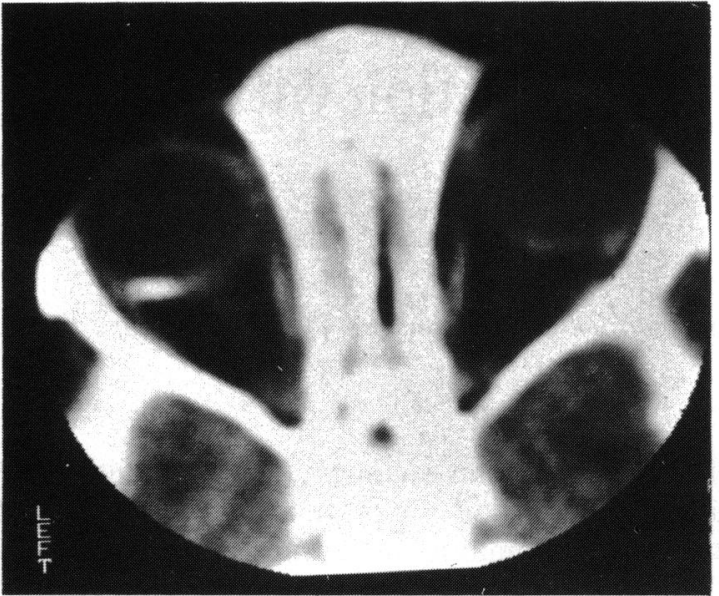

Fig. 1 CTscan showing calcified tumour in the posterior fundus of the left eye.

(Fig. 2). There was mild dilatation of the lateral ventricles but no shift of the midline structures. Cytological examination of the cerebrospinal fluid (CSF) showed small malignant cells with pyknotic nuclei (Fig. 3). No tissue was taken for histological examination.

The patient was treated with dexamethasone

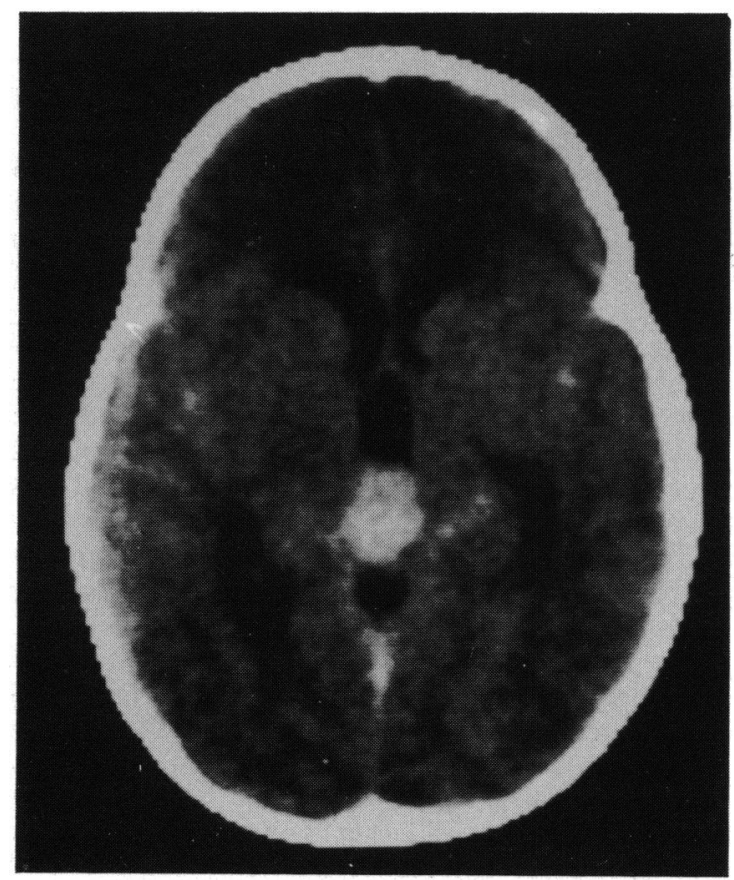

Fig. 2 CT scan showing an enhancing lesion in the region of the pineal gland and mild ventricular dilatation.

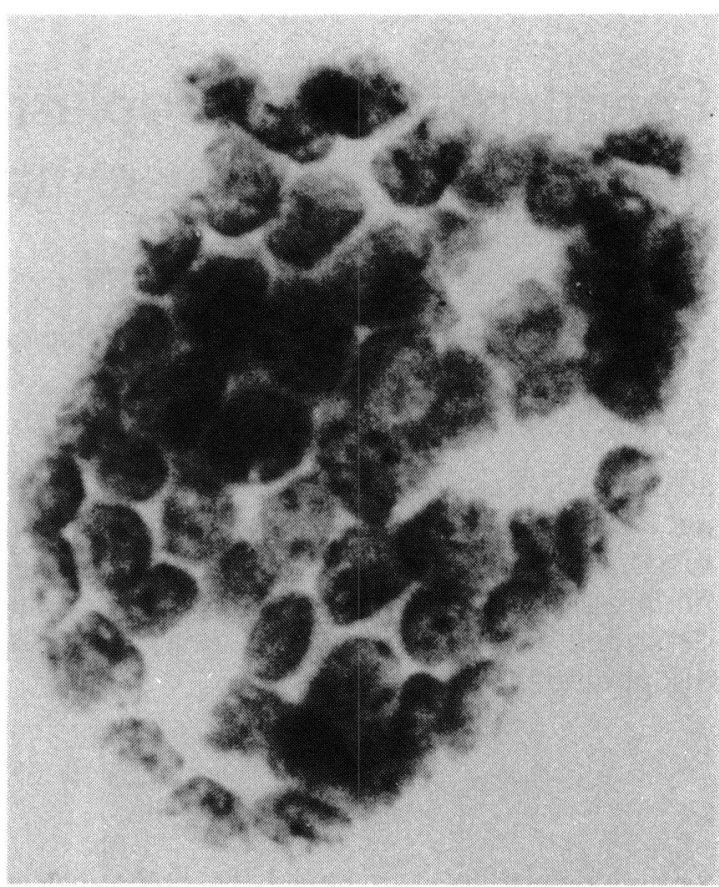

Fig. 3 Malignant cells in the cerebrospinal fluid showing moulded, small, dark pleomorphic nuclei and rosette formation. (Papanicolaou stain, $\times 400$ ).

$1.5 \mathrm{mg}$ six hourly initially, and this dose was gradually reduced over the following three weeks. The craniospinal axis was irradiated with cobalt-60. The head received $4000 \mathrm{cGy}$ in daily fractions of $120 \mathrm{cGy}$ followed by a further $500 \mathrm{cGy}$ to the pineal area. The spinal cord received 3800-4100 cGy also in daily fractions of $120 \mathrm{cGy}$. The radiotherapy was protracted over a period of three months because of myelosuppression and intercurrent infections.

A CT scan performed seven weeks after the start of the irradiation showed reduction in the size of the pineal lesion to $10 \times 10 \mathrm{~mm}$ and resolution of the hydrocephalus. Cytological examination of the CSF revealed many undifferentiated cells, most of which were degenerate.

The patient remained well for one month after the completion of irradiation, when the headaches, vomiting, and lethargy recurred. A further CT scan showed moderate dilatation of the ventricles, enlargement of the pineal lesion to $24 \times 14 \mathrm{~mm}$, and a second $20 \times 20 \mathrm{~mm}$ lesion in the region of the right caudate nucleus. The CSF contained numerous anaplastic tumour cells. Bone marrow biopsy was normal, and there was no evidence of other metastases. The patient was not given any further active treatment and died two months later. 


\section{POST-MORTEM FINDINGS}

The post-mortem interval was approximately six hours. The body weighed $10.5 \mathrm{~kg}$ and showed alopecia. The scalp and skull were otherwise unremarkable. The central nervous system (brain and spinal cord) and the posterior half of each eye together with attached optic nerves were fixed for six weeks in $10 \%$ formol saline prior to examination.

The external surface of the brain and spinal cord showed extensive superficial spread of tumour (Fig. 4a). Deposits of tumour were found on the surface of both optic nerves. A large haemorrhagic mass of tumour was present over the cribiform plate. It measured approximately $3 \mathrm{~cm}$ in diameter and involved the adjacent cerebral cortex on the inferior aspect of the frontal lobes. The optic chiasm was covered by a thick cake of tumour which extended into the third ventricle. Further deposits of tumour covered many of the cranial nerve roots. The neoplasm gave rise to a malignant meningitis involving much of the inferior aspect of the mid-brain, hindbrain and cerebellar hemispheres. Obstruction of the foramina of Luschka and Magendie was seen.

Similar subarachnoid spread of tumour gave rise to widespread involvement of the spinal cord and peripheral nerve roots. This process extended from the cervical region to the cauda equina. In the cervical and lumbar region, tumour was seen to invade the adjacent spinal cord.

The ventricular system was dilated owing to obstruction of the outlets of the fourth ventricle by tumour. Numerous subependymal deposits of tumour were present in the walls of the third ventricle. The pineal gland was largely destroyed by a mass of tumour measuring approximately $6 \mathrm{~cm}$ in diameter which protruded into the third ventricle and extended into the lateral walls of the thalamus and cerebral peduncles (Fig. 4b).

Histological examination of the tumour deposits showed a similar appearance in all lesions sectioned. The features were those of a poorly differentiated neuroectodermal tumour. The cells were poorly preserved. They had small dark basophilic nuclei and scant eosinophilic cytoplasm. Ill defined rosettes of tumour cells were seen. Perivascular growth of malignant cells was noted and much of the tumour was necrotic. Tumour was present within residual pineal tissue and possibly arose from this site.
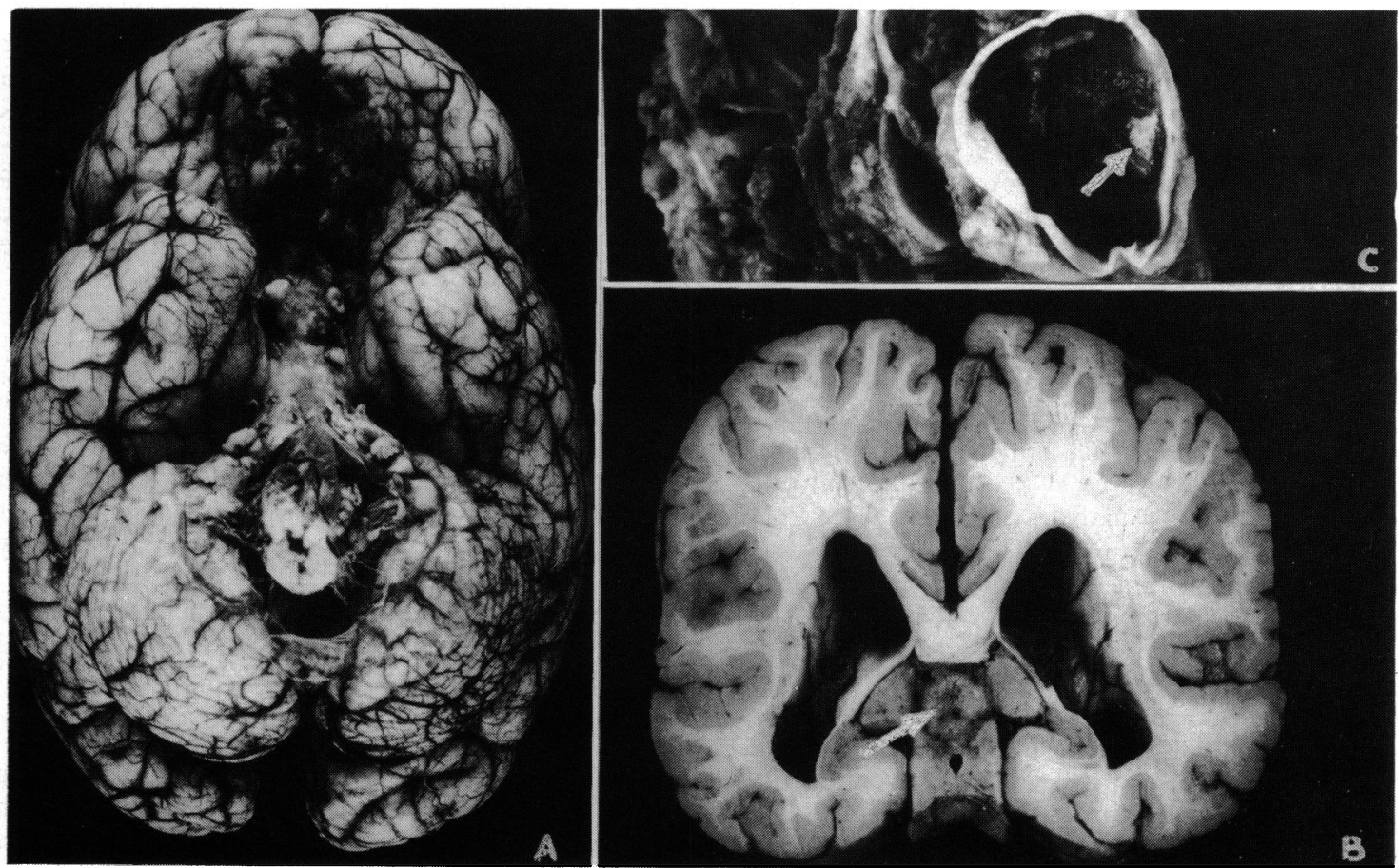

Fig. 4 A: The inferior surface of the brain showing a large haemorrhagic mass of tumour in the region of the olfactory nerves. Diffuse spread of tumour over the surface of cranial nerves and basal meninges was present. B: The coronal section of brain showing large tumour (arrow) in the region of the pineal gland which extended into the cerebral peduncles. Note the dilatation of the ventricular system. C: The small calcified retinoblastoma found at necropsy in the left retina (arrow). 
A small focus of involuted calcified retinoblastoma. was present in the lateral aspect of the left retina (Fig. 4c), but no residual viable tumour was present in the left eye. Although there was spread of tumour between the dura and the perineureum of the left optic nerve, the neoplasm was not seen to invade the lamina cribrosa. Tumour was not found in the right eye, but similar spread was present along the right optic nerve as far anteriorly as the lamina cribrosa.

Other post-mortem findings included a horseshoe kidney and bronchopneumonia, which was the immediate cause of death.

\section{Discussion}

In 1977 'the occurrence of independent brain tumours in two patients with retinoblastoma' was reported..$^{13}$ The lesions were both neuroblastic: one was sited in the pineal organ, the other in a retrochiasmal position. Subsequently an association has been reported between bilateral retinoblastoma and secondary primary putative retinoblastomas of the pineal. ${ }^{14}$ These workers proposed the concept of trilateral retinoblastoma and suggested that retinoblastoma may arise in vestigial photoreceptors in the pineal. This thesis has been reiterated subsequently. ${ }^{15}{ }^{16}$ The entity is considered to be clinicopathologically distinct from the more common case of retinoblastoma with a second primary sarcoma. ${ }^{1-12}$

In lower vertebrates the pineal organ is photoreceptor, ${ }^{19}$ comprises cells very similar to the rods and cones, and is derived from a similar neuroepithelial cell line. ${ }^{20}$ The mammalian pineal organ has lost its direct photoreceptor function but retains its sensitivity to photic stimuli through the inferior accessory optic tract mediated via the superior cervical autonomic ganglion. ${ }^{21} \mathrm{~A}$ similar situation is thought to pertain in humans. ${ }^{21}{ }^{22}$ While the occurrence of residual photoreceptor cells in the normal human pineal organ has not been documented, ${ }^{2.31}$ pinealoblastomas have been reported to show occasional features usually associated with retinoblastoma. ${ }^{32}$ In this context the review ${ }^{33}$ emphasising the similar appearance of primitive neuroepithelial tumours arising from different sites is of importance.

The common embryological origin of retinoblasts and pinealoblasts ${ }^{24}$ may well account for the susceptibility of both organs to the oncogenic factors operative in individuals carrying the retinoblastoma gene.

The present case may represent an example of this entity. The patient had a strong family history of hereditary retinoblastoma. He presented at the age of 7 weeks with a lesion of the left retina which had the appearance of a retinoblastoma and was treated accordingly. Subsequent post-mortem examination showed the presence of a calcified retinoblastoma restricted to the left retina, confirming the clinical diagnosis. Although the patient did not develop a tumour in the right eye, it is certain that he carried the retinoblastoma gene. All 11 patients in Bader and colleagues' series ${ }^{15}$ had bilateral tumours, and seven of them had a positive family history. They presented at an average age of 6 months compared with the range of 8-22 months in several series of bilateral retinoblastomas and 24-43 months for unilateral retinoblastomas. ${ }^{93413}$

The sequence of clinical events in the case reported here is suggestive of the development of a second primary lesion rather than a metastatic lesion. The neoplasm of the retina was treated successfully by local radiotherapy, did not recur, and at necropsy was calcified and limited to the retina. Two and a half years later the patient developed symptoms of an intracranial lesion. Although the histological appearance of this second lesion was not known until after death (and a full course of radiotherapy), CT scan localised the neoplasm to the region of the pineal organ. Despite the therapy the child developed numerous intracranial and spinal metastases and died.

At necropsy extensive disease in the central nervous system made assessment difficult. However, tumour was found only in the perineural subarachnoid space and not in the substance of either optic nerve. Viable tumour was not found in either retina nor crossing the lamina cribrosa of either eye. It was considered that the neoplastic cells in the subarachnoid space had metastasised from the intracranial site. The capacity of the lesion to spread in the subarachnoid space was evident by the extensive metastases covering spinal nerve roots.

At necropsy the second tumour showed the microscopic features of a poorly differentiated neuroepithelial neoplasm. In accordance with the view of Jakobiec and colleagues ${ }^{13}$ and Becker and Hinton ${ }^{33}$ only certain knowledge of the site of origin of the lesion could have separated retinoblastoma from pinealoblastoma. The early CT scan suggested that the lesion arose in the pineal organ, and at necropsy tumour was intimately part of residual pineal tissue. These factors favour the opinion that the second lesion was a new and distinct neuroepithelial neoplasm-a component of the so-called trilateral retinoblastoma.

The results of treatment, where it has been instituted, have been unsuccessful. ${ }^{131718}$ All patients have died except for two who were said to be alive with disease at one and 10 months respectively. ${ }^{15}$ In this case the response to aggressive treatment after early recognition of the entity was disappointing. However, the prolonged overall time of treatment, three months instead of six weeks, could have allowed 
tumour regrowth between treatments. The use of prior chemotherapy, therefore, with possible myelosuppression, is to be avoided. Alternatively these tumours may have a hypoxic element and be radioresistant.

This tumour had an initial volume of $2.4 \mathrm{~cm}^{3}$ and thus might be expected to have a cell volume of $2.4 \times 10^{4}$. A dose for $37 \%$ cell survival of $130 \mathrm{cGy}$ might therefore be expected to allow tumour eradication with a dose of $2860 \mathrm{cGy}$ if all cells were to be oxygenated. The failure of a dose 1.5 times larger than this would suggest the presence of hypoxic cells and thus strategies for improved therapy.

Thanks are duc to Dr Hannah-Recve Sanders, Medical Superintendent, Groote Schuur Hospital, for permission to publish this paper. We also thank Professor G Klintworth, of Duke University, North Carolina, for reviewing the histological sections.

\section{References}

1 Soloway HB. Radiation induced ncoplasms following curative therapy for retinoblastoma. Cancer 1966; 19: 1984-8.

2 Sagerman RH, Cassady JR, Tretter P, Ellsworth RM. Radiation induced ncoplasia following external beam therapy for children with retinoblastoma. $A J R$ 1969; 105: 529-35.

3 Jensen RD, Miller RW. Retinoblastoma: epidemiologic characteristics. $N$ Engl J Med 1971; 285: 307-11.

4 Strong LC, Knudson AG. Sccond cancers in retinoblastoma. Lancet 1983; ii: 1086.

5 Aherne G. Retinoblastoma associated with other primary malignant tumours. Trans Ophthalmol Soc UK 1974; 94: 938-44.

6 Schimkc RN, Lowman JT, Cowan GAB. Retinoblastoma and osteogenic sarcoma in siblings. Cancer 1974; 34: 2077-9.

7 Shah IC, Arlen M, Miller T. Osteogenic sarcoma developing after radiotherapy for retinoblastoma. Am Surg 1974; 40: 485-90.

8 Li FP, Cassady JR, Jaffe N. Risk of sccond tumours in survivors of childhood cancer. Cancer 1975; 35: 1230-5.

9 Lennox EL, Draper GJ, Sanders BM. Retinoblastoma: a study of natural history and prognosis of 268 cases. Br Med J 1975; iii: $731-4$.

10 Abramson DH, Ellsworth RM, Zimmerman LE. Non-ocular cancer in retinoblastoma survivors. Ophthalmology (Rochester) 1976; $81: 454$

11 Berg HL, Weiland AJ. Multiple ostcogenic sarcoma following bilateral retinoblastoma. J Bone Joint Surg 1978; 60A: 251-3.

$12 \mathrm{Kim} \mathrm{JH}$, Chu FC, Woodard HO, Melamed MR, Huvos A, Cantin J. Radiation induced soft tissue and bone sarcoma. Radiology 1978; 129: 501-8.

13 Jacobiec FA, Tso MOM, Zimmerman LE, Danis P. Retinoblastoma and intracranial malignancy. Cancer 1977; 39: 2048-58.

14 Bader JL, Miller RW, Meadows AT, Zimmerman LE, Champion, LAA, Voutc PA. Trilateral retinoblastoma. Lancet 1980; ii: 582-3.

15 Bader JL, Meadows AT, Zimmerman LE, et al. Bilateral retinoblastoma with cctopic intracranial retinoblastoma: trilateral retinoblastoma. Cancer Genet Cytogenet 1982; 5: 203-13.

16 Zimmerman LE, Burns RP, Wankum G, Tully R, Esterly JA. Trilateral retinoblastoma: ectopic intracranial retinoblastoma associated with bilateral retinoblastoma. J Pediatr Ophthalmol Strabismus 1982; 19: 320-5.

17 Donoso LA, Shields JA, Feldberg NT, Martyn LJ, Truex JT, D'Cruz CA. Intracranial malignancy in patients with bilateral retinoblastoma. Retina $1981 ; 1: 67-74$.

18 Judisch GF, Patil SR. Concurrent heritable retinoblastoma, pinealoma and trisomy X. Arch Ophthalmol 1981; 99: 1767-9.

19 Kappers JA. Structure and function of the epiphysis cerebri. In: Kappers JA, Schadé JP, eds. Prog Brain Res 1965; 10: 87-153.

20 Kappers JA. Introduction to the pineal. In: Wolstenholme GEW, Knight J, eds. The pineal gland. London: Churchill Livingstone, 1971: 3-25.

21 Truex RC, Carpenter MB. The diencephalon: the epithalamus. Human neuroanatomy. 6th cd. Baltimore, Williams and Wilkins, 1969: 458-59.

22 Wurtman RJ, Moskowitz, MA. The pineal organ. N Engl J Med 1977; 296: 1329-33, 1383-6.

23 Arieti S. The pineal gland in old age. J Neuropathol Exp Neurol 1954; 13: 482-91.

24 Olsson R. Subcommissural ependyma and pincal organ development in human foetuses. Gen Comp Endocrinol 1961 ; 1: 117-23.

25 Oksche A. Survey of the development of comparative morphology of the pincal organ. In: Kappers JA, Schadé JP, eds. Prog Brain Res 1965; 10: 3-29.

26 Quay WP. Histological structure and cytology of the pineal organ in birds and mammals. In: Kappers JA, Schadé JP, eds. Prog Brain Res 1965; 10: 49-86.

27 Scharenberg K, Liss L. The histologic structure of the human pincal body. In: Kappers JA, Schadé JP, eds. Prog Brain Res 1965; 10: 193-217.

28 Wildi E, Frauschiger E. Histological modifications of human pincal glands during childhood, adult life and ageing. In: Kappers JA, Schadé JP, eds. Prog Brain Res 1965; 10: 218-33.

29 Hülsemann M. Pineal histology in rhesus monkey and man. Acta Anat (Basel) 1967; 66: 249-78.

30 Japp E, Huxley M. The weight and degree of calcification of the pincal gland. J Pathol 1970; 105: 31-9.

31 Knight BK. Comparative anatomical structures of the pineal in man and chacma baboon (Papio ursinus) BSc Thesis. Salisbury: -University of Rhodesia, 1973.

32 Stcfano SQ, Manschot WA. Pinealoblastoma with retinoblastomatous differentiation. Brain 1979; 102: 321.

33 Becker LE, Hinton D. Primitive neuroectodermal tumours of the central nervous system. Hum Pathol 1983; 14: 538-46.

34 Dollfus MA, Auvert B. Quoted by Stallard HB. Multiple islands of retinoblastoma. Incidence rate and time span of appearance. Br J Ophthalmol 1955; 39: 241-3.

35 Mork T. Malignant neoplasms of the eye in Norway. Acta Ophthalmol (Kbh) 1961; 39: 824-31.

36 Jensen OA. Retinoblastoma in Denmark. Acta Ophthalmol (Kbh) 1965; 43: 821-40.

37 Leelawongs N, Regan CDJ. Retinoblastoma. A review of ten years. Am J Ophthalmol 1968; 66: 1050-60.

38 Knudson AG. Mutation and cancer. Statistical study of retinoblastoma. Proc Natl Acad Sci USA 1971; 68: 820-3.

39 Sevel D, Sealy R, Lawton E. Retinoblastoma at Groote Schuur Hospital, 1952-1972. Trans Ophthalmol Soc UK 1973; 93: 23-32.

40 Aherne GES, Roberts DF. Retinoblastoma-a clinical survey and its genetic implications. Clin Genet 1975; 8: 275-90.

41 Matsunaga E. Hereditary retinoblastoma. Penetrance, expressivity and age of onset. Hum Genet 1976; 31: 1-15.

42 Bonaiti-Pellie C, Briard-Guillemot ML, Feingold J, Fresal J. Mutation theory of carcinogenesis in retinoblastoma. $J$ Natl Cancer Inst 1976; 57: 269-76.

43 Stannard C, Lipper S, Sealy R, Sevel D. Retinoblastoma: Correlation of invasion of the optic nerve and choroid with prognosis and metastases. Br J Ophthalmol 1979; 63: 560-70. 